\title{
Management and Practice of Large-Scale Modern Coal Enterprises
}

\begin{abstract}
As the coal-dominated energy structure will remain unchanged in the short term, the sustainable development of the coal industry is still serving as one of the foundations for the sound development of the national economy. The construction of modernized mines based on "four orientations", that is, orientations of scale production, modern technology and equipment, informationized management and professional working team, has been rapidly enhancing its development in the recent decade. However, in the next decade or an even longer period, the industry, with the energy centre shifting to the West of China, will be exposed to new options and development in the layout, structure, model, technology, etc.
\end{abstract}

Keywords: coal industry, sustainable development, the four-orientation model

Since the beginning of reform and opening-up of China, especially in the recent decade, the coal industry has been developing rapidly, providing energy guarantee for the sustained prosperity of the national economy. In retrospect, it has presented a vivid picture of unusual and speedy development. However, China as a the biggest developing country needs sufficient, cheap, clean, safe and efficient energy supply to build a well-off society in an all-round way. As the coal-dominated energy structure cannot be changed in the short term and higher standards of energy conservation and low-carbon development are required, changes need to be made to the way of development of coal industry, bringing about various opportunities as well as challenges.

\section{The outstanding achievement in the recent decade}

The following statistics highlight the stride of the coal industry in the recent decade.

The output has been raised substantially. The coal output

Manuscript received December 3, 2013; accepted March 3, 2014

An Wang (西)

China Coal Energy Company Ltd., Beijing 100120, China

Email:wangan@chinacoal.com has tripled from 1 billion tons in 2000 (China Coal Information Institute, 2009, p. 5) to 3.25 billion in 2010 (Chinese National Coal Association, 2011, p. 15) to 3.65 billion in 2013, while China underwent the same process in 40 years from 300 million tons in 1960's to 1 billion tons in 2010 (China Coal Information Institute, 2009, pp. 3-5).

The production efficiency has been increased remarkably. The state-owned mines have raised the production efficiency of raw coal from 2.526 ton/ worker in 2000 (China Coal Information Institute, 2009, p. 94) to 5.68 in 2010 (China Coal Information Institute, 2012, p. 511). Among them, Shenhua Shendong Coal Group Co. Ltd. and China Coal Pingshuo Group Co. Ltd. have achieved 100 tons/ worker (China Coal Information Institute, 2011, p. 415; China Coal Information Institute, 2012, p. 516), which is twice to three times that of the developed countries like America. However, it took 36 years to improve the efficiency from 0.445 ton/ worker in 1950 to 1 in 1986 (China Coal Information Institute, 2009, pp. 84-91).

The safety level has been greatly elevated. In spite of the tripled production, the coal mines have reduced the death rate per million tons from 5.77 in 2000 (China Coal Information Institute, 2009, p. 192) to 0.749 in 2010 (China Coal Information Institute, 2011, p. 588) to 0.288 in 2013, successfully decreasing the death toll by $5 / 6$. Shendong and Pingshuo have maintained their death rate at 0.03 , lower than that of the advanced countries.

The coal industry owes its transformation to the innovations. In the mid- and late 1990s, with the rapid development of relevant technologies and equipment, the mines integrated advanced technologies and management skills and carried out a series of revolutionary innovations based on the idea of scale production, modern technology and equipment, informationized management techniques and professional working team, which changed their development patterns and guided the industrial development.

\section{The restraints on coal enterprise from 1982 to 1992}

During this period, China's coal industry made some slow progress but failed to make a transformation. The largest 
mine could produce only about 3 million tons of coal per year and most only hundreds of thousand or even tens of thousand tons, creating a typical impression of the coal industry, "an industry of small scale, backward equipment, low efficiency, high pollution and serious casualties".

\subsection{Low capacity and small-scaled single well}

In the early $1990 \mathrm{~s}, 60 \%$ of coal was produced by small mines, especially those of township with the maximum annual capacity of 50,000 to 300,000 tons. Except few with million-ton annual capacity, most state-owned mines produced only 300,000 to 900,000 tons per year.

\subsection{Complicated system, backward technology and equip-} ment

With the complicated production system, popular multi-panel layouts, and much lower mining technology and mechanization than the advanced countries, the production remained inefficient.

2.3 Serious environmental pollution and contradiction between production and environmental protection

The traditional way of coal production often ignored the environmental protection and inevitably led to pollution. With gangue hills, waste water and coal dust, the surface eco-system deteriorated severely.

2.4 Complicated management system, overstaffed organization, over-intensive labour and low working efficiency

In traditional mines, manpower and material resources were seriously wasted. A 0.3 million tons per year capacity mine normally employed 10,000 workers, a 3 million tons per year capacity mining area 40,000 , and some 20 million tons per year capacity miming bureau over 100,000, which left a heavy burden on the enterprises.

Under such a background, what was behind the decade-long transformation of the coal industry? Although many factors contributed to the progress, it was an undisputable fact and historical witness that the construction of some typical modern mines of world-class changed the development pattern and guided the orientation.

\section{The "four-orientation" model as the aim of coal enterprises' innovation}

The construction of modernized coal mines based on "four orientations", that is, orientations of scale production, modern technology and equipment, informationized management and professional working team, marked the appearance of new forces of production and new directions of innovation, embedded new philosophies of industrial innovation concerning coal industry (Wang, 2008), and presented new integrations of technological and managerial innovations.

3.1 The scale production and the technological and equipment modernization by simplified systems and improved tools

Engineering design and practice are generally realized under the guidance of creative ideas or thoughts. Simplified but smooth systems of mining engineering come from continuous optimization of engineering management, based upon profound mastery of such objective rules as brought by natural environment and geographical circumstances, upon proficient application of mining technology and modern equipment, and upon never-ceasing creations of design ideas. It takes best coordination of subjective and objective factors to secure best economic and social benefits of engineering.

In the process of mining system optimization, the multi-panel model is turned into the zero-panel to build the underground "express way". Take Shendong as an example. By borrowing the "express way" idea and by integrating and innovating advanced technologies, it successfully replaced the complicated traditional multi-panel system with the simple and smooth zero-panel system capable of a massive working face, which broke the bottleneck of traditional mines and created conditions for safe and efficient production. The width of working face was extended from 150 metres to 300 metres, and the advancing length from 1,500 metres to 6,000 or even 8,000 metres. The output for a single working face of fully-mechanized mining amounted to 8 million tons, and the pit type rose to 10 to 20 million tons. Shendong established the model of "per surface of a pit with 300 workers for 10 million tons and two surfaces of a pit with 500 workers for 20 million tons". Such a modern mine-running model of Shendong has been popularized, which saves $95 \%$ of labour as used by traditional coal mines. And, with scale production, such a model makes ten-million-ton capacity pits and hundred-million-ton capacity mining areas possible.

A modern mining area must be well-equipped. Howev-

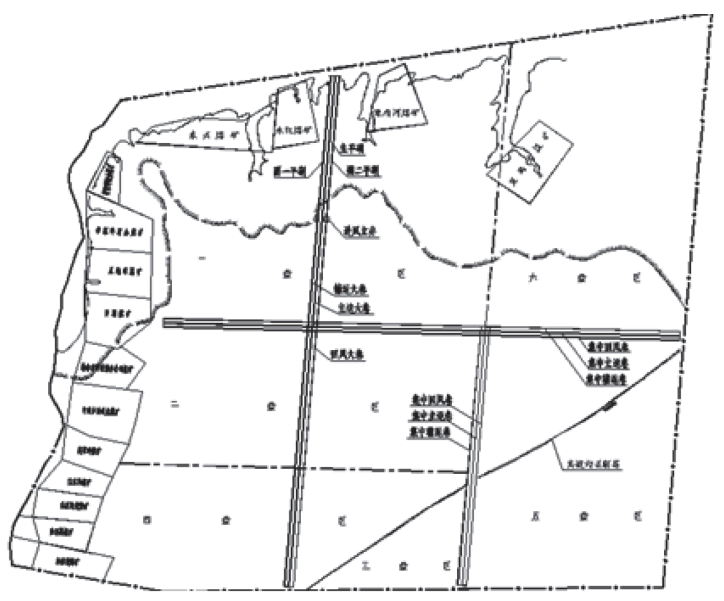

Figure 1. The multi-panel schematic design of Shendong Huojitu Pit. 
er, high-standard equipment does not mean considerable investment. The key lies in the effect. The construction of an advanced mine depends on two major changes: first, more investment on technology and equipment instead of sinking and drifting engineering; more expense on working face equipment instead of the system; second, cost control of pit construction through the employment of high-tech equipment. With the technological and managing innovations, coal mines emerge from an industry of long investment-return cycle into that of short investment-return cycle. Shendong Huojitu Pit had been designed to consist of 6 panels, whose final cancellation saved over 400 million RMB, a considerable sum compared with 200 million RMB for a set of modern fully-mechanized equipment.

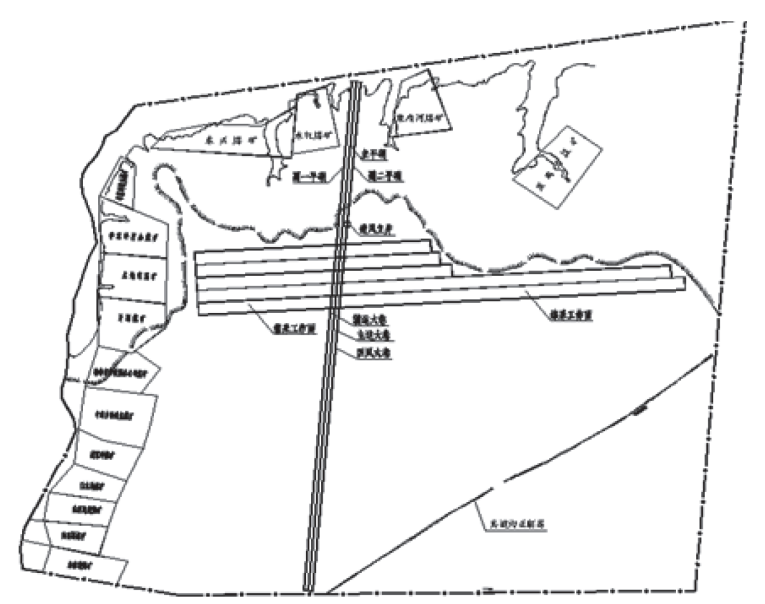

Figure 2. The zero-panel schematic design of Shendong Huojitu Pit.

3.2 Informationized management techniques and professional working team by system integration and model innovation

Engineering innovation largely arises from system integration. Transformation of engineering can be achieved only through superior integration of innovations to improve the functions of the project as a whole with the help of breakthroughs in key technologies. In the process of constructive advancement to scale production and modernization, a series of key technologies were integrated and innovated. It is true of the ten-million-ton capacity mining technology system in the most representative Shendong mining area, where engineers, made systematic analyses of the relationship among mining, drilling, mechanizing, transporting, ventilating and electrifying, developed and applied such core technologies as ventilation system of inclined adits of massive section with multiple roadways, superb working face with zero-panel layout, long-short wall mining, trackless rubber-tyred subsidiary haulage, underground informationization, and direct power supply by ground-box through drill hole.

The ventilation improvement of inclined adits based on massive section, multi-roadway, low air pressure and high air flow broke the bottleneck of traditional mines, bringing the capacity into full play and the coal spontaneous combustion and gas accumulation under control. The popularization of trackless rubber-tyred subsidiary haulage tackled the problem of excessive transportation links, manpower and accidents and guaranteed the efficient transportation for the super-long working face. The solution to the support difficulty resulting from the double-lane mining dynamic pressure ensured the ventilation safety of long-distance drilling. The direct power supply by ground box through drill hole reduced the voltage loss in multi-level power supply. The use of highly-reliable drilling equipment realized fast drilling and fast mining and restrained the spontaneous combustion of working face. The integration of innovations mentioned above makes the construction of super fully-mechanized working faces possible, increasing the size by 8 to 9 times and successfully turning the complicated and inefficient traditional multi-panel layout into the simple and efficient zero-panel design, which greatly simplifies the operation links and substantially reduces the manpower and the investment.

It is a very effective measure for the reform of coal mines to spread information technology. For coal mining, an industry of high risk, less manpower means fewer accidents, and the introduction of informational techniques has proven effective to some extent. In 1998, while information technology was just introduced in Beijing and Shanghai, Shendong had already applied it to the equipment for underground operation, realizing the direct point-to-point or point-to-face control as well as the informational and remote control of underground transportation, ventilation, power supply, water supply and drainage, fully-mechanized mining, ground preparation and loading, and enhancing the automation of coal mining, which largely reduced the underground workers, simplified the operation links and lowered the labour intensity. Given the traditional management and production patterns, Shendong should have employed 59,000 workers for a mining area with the capacity of 50 million tons per year, but the number, after the information reform, was reduced by $95 \%$ to 7,000 for an area with the capacity of 100 million tons per year. At present, advanced information technologies are widely used in large-sized coal enterprises.

The cultivation of core team was strengthened to foster a professional working team. Man functions as the ultimate decisive factor in the development of an enterprise. In constructing a modern large-sized mine with scale production, a new simple and efficient model was established by the professional internal management for the core business, the building-block style human resources management, and the professional external service for the non-core business. According to such a mode and the situation of core business, the enterprises provided various educational resources to strengthen the training and to foster a professional team, which eventually led to the building-block style human resources management and the booming development.

In the recent decade, some modern mines, by the "four-ori- 
entation" model, have established a new set of technological specifications for coal enterprises which promoted the professionalization and the update on China-made equipment, and built some 10-mllion-ton capacity mines and 100-million-ton capacity mine areas which enhanced the technological upgrade and the management innovation of the mining industry. "Shendong model" has been speedily copied.

\section{The options of sustainable development for coal enterprises}

In ten or more years in the future, for the sake of sustainable development, it is necessary to take comprehensive measures to promote healthy and speedy advancement of coal industry, with large-scale coal bases as construction priorities, largescale coal enterprises as the centres, reform and innovation in science and technology as propelling forces. Measures include optimization of industrial deployments, innovation of industrial patterns, elevation of industrial technologies, and clarification of industrial approaches.

4.1 Optimization of industrial deployments as the precondition for sustainable development of coal enterprises

As the resources of the East tend to be exhausted, many industries are to be upgraded, and some to be shifted to the West, which will accordingly lead to the westward movement of energy development. Meanwhile, the improvement of infrastructure and the technological advancement of energy conversion and transmission guarantee the new polyvalent industrial layout of the West based on energy industry. Therefore, the optimization of layout is not only a must but also a significant opportunity to stimulate the domestic demand and upgrade the industries.

With the energy production layout shifted to the West, if the new round of Western development campaign can be exploited properly, the Eastern and Western industries can become mutually supportive, which will eventually narrow the gap between the East and the West and reduce the severity of smog in the East. The East should gradually establish more high-end industries with low-energy consumption to reduce environmental pollution and share the benefits brought by technological improvement. The West, while ensuring the energy supply, should build the polyvalent industry layout based on energy industry to profit from the industrial transfer and promote energy conservation.

The new layout should enhance its coordination with its energy advantage, which reflects the integrity, regionalization and correlation based on the resource richness and helps avoid the disordered segmentation of resources; with its means of energy transmission, which leads to the establishment of the index system of critical decision for a scientific layout by considering on the premise of new energy transmission technologies the economy and energy consumption index of unit distance for each means, and supports the op- timization with the most desirable way of transmission; and with its economic growth, which realizes the industrial integration and economic diffusion by forming a network-like industrial layout based on energy bases, urban agglomerations, economic core zones and important economic belts.

4.2 Adjustment of industrial structures as the necessary choice for sustainable development

A new industrial structure of low energy consumption, low emission and high efficiency needs to be built on the base of the clean utilization of coal resources. "Coal conversion" is both the requirement of the industrial restructuring and the strategic measure of energy safety, for it presents an obvious economical advantage in the background of high oil price. To achievement this objective, conditional conversion should be taken as the principle, and mature technology as the foundation. In this process, sufficient attention should be paid to the capacity of environment and water resources in order to adjust the measures to the local conditions and make scientific development, which highlights the comparative advantage of the area. The areas rich in coal resources should attach importance to the development of electric power industry, modern coal chemical industry, new energy industry and relevant new material industry as well as equipment manufacturing industry. With its sample projects in coal oil, coal gas, coal alcohol ether, and coal olefin, the coal chemical industry whose key lies in orderly and moderate development is expected to make even more significant contribution to the new heavy chemical industry, which will exert active influence on the energy restructuring.

Efforts should be actively made to enhance the new energy industry, including wind power, hydro-power and solar power and combine traditional energies and new energies properly. Wind-power and solar-power resources are widely spread in the West and overlaps largely with fossil fuels. Mature high-capacity, high-efficiency and long-distance power transmission technologies such as the ultra-high voltage network will shift the coal-fired power centre to the West and provide support for the scale production and transmission of unstable energies like solar power and wind power, contributing to a benign interaction between energy development and supply. Furthermore, the proper utilization of nuclear power will not only benefit the clean and efficient use of energy but also release the pressure of energy transmission effectively. Therefore, an overall planning and coordinated development will prove critical.

4.3 Innovation of industrial patterns as the foundation for sustainable development

The target should be set on the industrial agglomeration. The energy industry in the West must stick to the industrial pattern characterized with agglomeration, scale production and modernization. Industrial parks must be constructed on the overall planning to decide the industrial orientation by 
the very idea of agglomeration of industries in the industrial base and integration of projects in the industrial park. Thus, the optimization of industrial layout will accelerate the agglomeration and modernization of industrial model, which in turn will promote the base-oriented, park-based and agglomerated industrial layout, realizing their coordinated development and establishing energy-conserving industrial models.

Poly-generation circular economy should be taken as the aim of development. The construction of industrial parks should focus on the establishment of large-sized enterprises and base itself on the comprehensive utilization of resources. If the links between projects and between enterprises are built, resources can be converted more than once and their cascade utilization realized, forming the metabolic and symbiotic relationship between industries and bringing about the comprehensive use of resources. The employment of coal-derived poly-generation technology enables the simultaneous production of electric power, thermal energy/steam, liquid fuels and chemical products. Some areas in Inner Mongolia and Shaanxi Province have set successful examples by using their abundant resources of coal, gas, oil and salt.

4.4 Upgrading of industrial technologies as the root ground for sustainable development

Technological advancement always serves as the eternal drive for industrial development. The related industry should intentionally bring together new technologies and take the advantage in competition. The broader domain the integration covers, the better innovation it will produce.

Active efforts should be made on the deep integration of industrialization and informationization. When the informationized pattern matches the industrial one, and new technologies, materials and equipment are combined as a whole, the industry will tend to be large, simple and informationized, which will create new technologies as well as new production capabilities and models.

The rise of industrial standards can enhance the technological upgrading. Standards arise from effective integration of sophisticated technology and management. To raise the standard means to raise the access threshold, which will inevitably improve the enterprise's innovative ability, accelerate the industrialization and commercialization of high technologies, and promote the technological upgrade.

The technological innovation is capable of resolving the contradiction between industrial development and environmental protection. Although the eco-environment always remains a solid restriction on coal development and conversion, it is not correct to view this conflict from a passive and static perspective. In fact, so long as the industry is properly selected, the pattern established, the technologies employed, and the environmental protection facilities improved, the negative influence can be avoided and the eco-environment may even be restored. The technological innovation of coal mining provides huge space for the environmental protection and the comprehensive utilization of water resource, which can be seen in some areas of the West with both rapid industrial development and improved eco-environment.

\section{Conclusion}

As the sustainable development of the coal industry is bound up with that of economy and society, it becomes both a realistic option and a historical necessity. In the past decade, it was because the developmental trends of coal industry were well governed that the "four-orientation" model could perfectly meet the objective needs of productivity growth of coal mines. In the coal industry, a series of such innovations as the "four-orientation" model have enhanced three historic changes, the changes from the labor-intensive to the technology-intensive, from the high-risk to the intrinsically-safe, and from the environmental-pollution to the environmental-protection; resolved two conflicts, conflicts between high production and production safety, and between economic development and environmental pollution; and established a scientific mining system characterized with high output, high efficiency, safety, high recycling rate and environmental protection. Such innovations set good examples for the construction of modern coal bases in China. In the future, the increasing size and scale of coal mines will result in more concentrations of industries and industrial capacities. The integrated construction model will accelerate the industrial upgrading, and help realize in the production operation the industrial chain economy and the circular economy as well as the models of base production, park production and poly-generation production. The technological advancement will exert even stronger influence on the reform of industrial forms and management patterns.

\section{References}

China Coal Information Institute.(2009). China coal industry yearbook 2008. Beijing: China Coal Industry Publishing House

China Coal Information Institute.(2011).China coal industry yearbook 2010. Beijing: China Coal Industry Publishing House

China Coal Information Institute.(2012). China coal industry yearbook 2011. Beijing: China Coal Industry Publishing House

Chinese National Coal Association. (2011). Annual report on coal industry in China 2010. Beijing: China Economy Press

Wang, A. (2008). The philosophical application in the construction of mine engineering in Shendong mining area. Sci-Tech Progress and Policy, 25 (10), 8-11 